\title{
Comparative evaluation of antibody response in rabbits vaccinated with toxoid, alum precipitated and alum precipitated oil adjuvant enterotoxaemia vaccines
}

\author{
Ajay Kumar Rai, V. K. Chaturvedi, T. G. Sumithra, S. S. Chougule, Bincy Joseph and M. S Murugan \\ Division of Bacteriology and Mycology, \\ Indian Veterinary Research Institute, Izatnagar -243122, Bareilly (U.P.), India \\ Corresponding author: T. G. Sumithra, email:sumithravet@gmail.com \\ Received: 28-08-2012, Accepted: 24-09-2012, Published online: 19-01-2013
}

How to cite this article: Rai AK, Chaturvedi VK, Sumithra TG, Chougule SS, Joseph B, Murugan MS (2013) Comparative evaluation of antibody response in rabbits vaccinated with toxoid, alum precipitated and alum precipitated oil adjuvant enterotoxaemia vaccines, Vet. World 6(4):200-204, doi: 10.5455/vetworld.2013.200-204

\begin{abstract}
Aim: To compare the newly formulated enterotoxaemia vaccine having oil and alum adjuvants, with presently available toxoid and alum precipitated vaccines.

Materials and Methods: Three types of enterotoxaemia vaccines, namely toxoid (TV), alum precipitated (APV) and alum precipitated oil adjuvant vaccine (AOV) were prepared using a highly toxigenic strain of Clostridium perfringens type D procured from Division of Biological Standardization, IVRI, Izatnagar. Humoral immunity generated in rabbits with these vaccines was then quantified using indirect enzyme-linked immunosorbent assay (ELISA) and mice neutralization test (MNT).

Results: Out of three enterotoxaemia vaccines tested, alum precipitated oil adjuvant vaccine produced higher and persistent antibody titre for more than 45 days without any booster dose and did not produce any untoward reactions at the injection site. Alum precipitated vaccine elicited better and persistent immune response than toxoid vaccine though it was less than alum precipitated oil adjuvant vaccine. In MNT, alum precipitated and alum precipitated oil adjuvant vaccines showed protection at $45^{\text {th }}$ day of post vaccination while toxoid vaccine showed only up to $28^{\text {th }}$ day.

Conclusion: Results of the study unfolded the synergistic role of adjuvants in the induction of better and persistent immune response and also indicated the superiority of alum precipitated oil adjuvant vaccine over the currently available toxoid and alum precipitated enterotoxaemia vaccines.
\end{abstract}

Keywords: alum precipitated oil adjuvant vaccine, Clostridium perfringens Type D, enterotoxeamia, indirect enzyme-linked immu-nosorbent assay, mice neutralization test

\section{Introduction}

Enterotoxaemia caused by Clostridium perfringens is a devastating disease of small ruminants with very short clinical course [1] and therefore therapeutic interventions often do not work. Among the five toxinotypes of this organism, type D producing epsilon toxin is principally associated with caprine and ovine enterotoxaemia $[2,3]$. Though this disease can be prevented by epsilon toxoid vaccination [3-5] double initial dose is currently recommended for both sheep and goats, followed by a booster every year in sheep [6] and every 3-4 months in goats [7]. Hence, the present vaccination strategy requires heavy input of resources along with the difficulty in tracing animal for booster dose. Therefore there is need for developing a new enterotoxaemia vaccine which can induce a sustained immunity [8].

Aluminium salts, the widely used adjuvants in many human and veterinary vaccines [9] can provide only a short duration of immunity. Therefore oil has been used along with these to form depot at vaccination site. The duration of immunity provided by these vaccine formulations are longer and amount of antigenic mass required is also less [10]. Since the major limitations of the enterotoxaemia vaccine lies with antigenic mass and duration of immunity, these drawbacks can be very well addressed by the alum precipitated oil adjuvant formulations. Realizing these needs, a new alum precipitated oil adjuvant enterotoxaemia vaccine was prepared in the present study and then compared with commercially available toxoid and alum precipitated vaccines in rabbit model.

\section{Materials and Methods}

Bacterial cultures: A highly toxigenic strain of $C$. perfringens type $\mathrm{D}$ procured from Division of Biological Standardization, IVRI, Izatnagar, was used for vaccine preparation. The organisms were characterized morphologically, culturally and by toxigenicity studies. Molecular characterization was done by PCR using genomic DNA isolated from the strain and etx specific primers (F- 5'AAG GAT CCA AGT TTA GCA ATC GCA TCA GC3'; R - 5'TAC CTC GAGTTATTT TAT TCC TGG TGC C3').

Experimental animals: Clinically healthy Swiss albino mice of either sex weighing not less than $18-20 \mathrm{~g}$ and albino rabbits (Lupus cuniculus) of either sex weighing not less than $1 \mathrm{~kg}$ were procured from the Laboratory Animal Resources (LAR) Section, I.V.R.I, and Izatnagar and maintained under standard conditions of 
Table-1. Anti-epsilon ELISA titres (P/N ratio) of rabbits immunized with TV

\begin{tabular}{llllll}
\hline Rabbit & \multicolumn{5}{c}{ Days post vaccination } \\
\cline { 2 - 6 } & $\mathbf{7}$ & $\mathbf{1 4}$ & $\mathbf{2 1}$ & $\mathbf{2 8}$ & $\mathbf{4 5}$ \\
\hline 1 & 1.536 & 2.390 & 1.774 & 1.500 & 1.198 \\
2 & 1.421 & 2.201 & 1.579 & 1.527 & 0.960 \\
3 & 1.875 & 2.988 & 2.710 & 2.310 & DEAD \\
4 & 2.603 & 3.439 & 3.402 & 3.027 & 2.442 \\
Mean+SE & $1.86 \pm 0.26^{\text {ab }}$ & $2.75 \pm 0.28^{\text {ab }}$ & $2.37 \pm 0.42^{\text {ab }}$ & $2.09 \pm 0.36^{\text {ab }}$ & $1.53 \pm 0.46^{\mathrm{a}}$ \\
\hline
\end{tabular}

a, b and c represents significant difference level 1, 2 and 3

Table-2. Anti-epsilon ELISA titres (P/N ratio) of rabbits immunized with APV

\begin{tabular}{|c|c|c|c|c|c|}
\hline \multirow[t]{2}{*}{ Rabbit } & \multicolumn{5}{|c|}{ Days post vaccination } \\
\hline & 7 & 14 & 21 & 28 & 45 \\
\hline 5 & 1.658 & 1.725 & 2.524 & 2.893 & 1.856 \\
\hline 6 & 1.347 & 1.429 & 2.710 & 1.920 & 1.829 \\
\hline 7 & 1.549 & 1.659 & 2.182 & 2.137 & 1.840 \\
\hline 8 & 1.402 & 1.844 & 2.408 & 2.997 & 2.417 \\
\hline Mean+SE & $1.49 \pm 0.07^{a}$ & $1.66 \pm 0.174^{\mathrm{ab}}$ & $2.46 \pm 0.22^{c}$ & $2.49 \pm 0.14^{c}$ & $2.01 \pm 0.11^{b}$ \\
\hline
\end{tabular}

a, b and $c$ represents significant difference level 1, 2 and 3

Table-3. Anti-epsilon ELISA titres ( $\mathrm{P} / \mathrm{N}$ ratio) of rabbits immunized with AOV

\begin{tabular}{|c|c|c|c|c|c|}
\hline \multirow[t]{2}{*}{ Rabbit } & \multicolumn{5}{|c|}{ Days post vaccination } \\
\hline & 7 & 14 & 21 & 28 & 45 \\
\hline 9 & 1.082 & 3.481 & 3.045 & 3.012 & 2.939 \\
\hline 10 & 1.280 & 1.559 & 2.423 & 2.546 & 2.160 \\
\hline 11 & 1.224 & 1.399 & 1.728 & 1.730 & 1.618 \\
\hline 12 & 1.368 & 3.006 & 3.109 & 2.856 & 1.872 \\
\hline Mean+SE & $1.24 \pm 0.06^{a}$ & $2.36 \pm 0.52^{b}$ & $2.58 \pm 0.32^{b}$ & $2.54 \pm 0.29^{b}$ & $2.15 \pm 0.29^{\mathrm{ab}}$ \\
\hline
\end{tabular}

$\mathrm{a}$ and $\mathrm{b}$ represents significant difference level 1 and 2 .

nutrition and management. The animal ethics committee of the Indian Veterinary Research Institute, Deemed University approved the study.

Preparation of toxoid vaccine (TV): The production medium [11] was inoculated with the seed culture and incubated at $37^{\circ} \mathrm{C}$ overnight. An active growth was evident by vigorous gas production within 3 hours of incubation. After 24 hours, growth was tested for purity and aerobic sterility. Trypsin was then added to a final concentration of $0.25 \%$ and incubated at $37^{\circ} \mathrm{C}$ for one and half hours. Two $\mathrm{ml}$ of the product removed from each flask was pooled and centrifuged. $0.1 \mathrm{ml}$ of serial dilutions of this supernatant was injected $\mathrm{i} / \mathrm{v}$ into two healthy adult mice (18-20g weight) and the minimum lethal dose per $\mathrm{ml}$ was determined. After trypsinization rest of the culture was pooled, formalized with $0.5 \%$ formalin and incubated at $37^{\circ} \mathrm{C}$ for 15 days. It was tested for aerobic and anaerobic sterility and then stored at $4^{\circ} \mathrm{C}$. Atoxicity test was carried out in mice by $\mathrm{i} / \mathrm{v}$ inoculation of $0.2 \mathrm{ml}$ of prepared TV.

Preparation of alum precipitated vaccine (APV) : $\mathrm{pH}$ of $100 \mathrm{ml}$ TV was adjusted to 6.5 by using sterile $1 \mathrm{~N}$ sodium hydroxide solution. $20 \%$ solution of hot sterile alum in distilled water was then added to a final concentration of $1 \%$ and kept overnight at room temperature with agitation. Finally it was stored at $4^{\circ} \mathrm{C}$.

Preparation of alum precipitated oil adjuvant vaccine (AOV): $67.5 \mathrm{ml}$ of sterile liquid paraffin and $7.5 \mathrm{ml}$ of melted lanolin (9:1) was transferred aseptically to a commercial blender and mixed for 20minutes at room temperature. After adding $100 \mathrm{ml}$ of alum precipitated toxoid vaccine to the blender emulsification was carried out at room temperature giving 4 runs of $5 \mathrm{~min}$ each, with about 5 min gap between each run. The vaccine was stored at $4^{\circ} \mathrm{C}$ overnight and re-emulsified next day.

Sterility, safety and stability testing of vaccines: Sterility tests of all three vaccines were done by inoculating in nutrient agar and nutrient broth. The safety of the vaccines was tested in six swiss albino mice and made a continuous observation for any untoward effects up to 10 days. For testing the stability all the prepared vaccines were kept at $4^{\circ} \mathrm{C}$ as well as at room temperature for 14days before using them for immunization.

I mmunization: The antigenic mass was kept constant in all three vaccines and then each rabbit having not less than $1 \mathrm{~kg}$ weight (4 animals in each group with total 4 groups including control) was immunized with a single dose of $2 \mathrm{ml} \mathrm{TV}, 2.5 \mathrm{ml}$ of APV and $4 \mathrm{ml}$ of AOV by deep $\mathrm{i} / \mathrm{m}$ route. Serum collection was done on 0,7 , 14, 21, 30, 45 days DPV.

\section{Determination of immune response}

Preparation of antigen (Epsilon toxin): The cells from the production media were pelleted by centrifugation at $6000 \mathrm{rpm}$ for 30 minutes. Then the clear supernatant was concentrated by ammonium sulphate precipitation at a final concentration of $45 \%$ with stirring overnight. 
Table-4. Anti-epsilon ELISA titres (P/N ratio) of rabbits immunized with different vaccines

\begin{tabular}{llllll}
\hline Vaccine & \multicolumn{5}{c}{ Days post vaccination } \\
\cline { 2 - 6 } & $\mathbf{7}$ & $\mathbf{1 4}$ & $\mathbf{2 1}$ & $\mathbf{2 8}$ & $\mathbf{4 5}$ \\
\hline TV & $1.86 \pm 0.26^{\mathrm{ab}}$ & $2.75 \pm 0.28^{\mathrm{ab}}$ & $2.37 \pm 0.42^{\mathrm{ab}}$ & $2.09 \pm 0.36^{\mathrm{ab}}$ & $1.53 \pm 0.46^{\mathrm{a}}$ \\
APV & $1.49 \pm 0.07^{\mathrm{a}}$ & $1.66 \pm 0.174^{\mathrm{ab}}$ & $2.46 \pm 0.22^{\mathrm{c}}$ & $2.49 \pm 0.14^{\mathrm{c}}$ & $2.01 \pm 0.11^{\mathrm{b}}$ \\
AOV & $1.24 \pm 0.06^{\mathrm{a}}$ & $2.36 \pm 0.52^{\mathrm{b}}$ & $2.58 \pm 0.32^{\mathrm{b}}$ & $2.54 \pm 0.29^{\mathrm{b}}$ & $2.15 \pm 0.29^{\mathrm{ab}}$ \\
\hline
\end{tabular}

$a, b$ and $c$ represents significant difference level 1, 2 and 3

Table-5. Results of Mice Neutralization test (MNT)

\begin{tabular}{llllll}
\hline Vaccine & \multicolumn{5}{c}{ Days post vaccination } \\
\cline { 2 - 6 } & $\mathbf{7}$ & $\mathbf{1 4}$ & $\mathbf{2 1}$ & $\mathbf{2 8}$ & $\mathbf{4 5}$ \\
\hline TV & No Death & No Death & No Death & No Death & Death \\
APV & No Death & No Death & No Death & No Death & No Death \\
AOV & No Death & No Death & No Death & No Death & No Death \\
\hline
\end{tabular}

The precipitate was separated by centrifugation and dialyzed against $0.01 \mathrm{M}$ Phosphate buffer ( $\mathrm{pH} 7.5)$ and then concentrated using polyethylene glycol-6000. Further purification was done by DEAE cellulose anion exchange chromatography. The peak fractions were pooled, concentrated and activated to check toxicity then formalized and the protein concentration was estimated. The confirmation of purified epsilon toxin was done by SDS-PAGE and western blot analysis.

Production of hyper immune serum: Two ml of APV was injected s/c in rabbit as first dose of antigen. Thereafter four $2 \mathrm{ml}$ of TV injections were given at weekly intervals. After $4^{\text {th }}$ injection the rabbit was bled to check the antibody titre. The rabbit with good antibody titre were finally bled by ear vein. The serum was stored at $-70^{\circ} \mathrm{C}$.

Indirect enzyme-linked immunosorbent assay (ELISA): For the analysis of immune response indirect ELISA was done. Sera of rabbits grown up in clostridia free environment was used as negative sera. The proper dilution of the antigen (Stock- $1 \mathrm{mg} / \mathrm{ml}$ ) and serum was determined using chequer board method. Titre of the individual serum sample was expressed in positive/ negative ratio ( $\mathrm{P} / \mathrm{N}$ ratio).

Mouse neutralization test (MNT): In MNT, $1 \mathrm{ml}$ of pooled sera from each group was mixed with $1 \mathrm{ml}$ of the epsilon toxin containing 300MLD and kept at room temperature for half an hour. $0.2 \mathrm{ml}$ of this mixture was injected intravenously into two mice. Two mice were given $0.1 \mathrm{ml}$ of the diluted toxin containing 300 $\mathrm{MLD} / \mathrm{ml}$ to make control group.

\section{Results}

Characterization of C. perfringens type D: The procured strain of $C$. perfringens type D showed typical morphological, cultural and toxigenic properties. During molecular characterization the desired 997 bp product was obtained (Fig-1). The toxin titre was 2000 MLD/ $\mathrm{ml}$.

Sterility, safety and stability testing of vaccines: Final vaccines inoculated in different media did not show any growth denoting their sterility. All the vaccines were found safe in mice. AOV did not show separation of different phases (oil and water) when kept at $4^{\circ} \mathrm{C}$ and room temperature indicating its stability.

Preparation of antigen: On analysis of purified toxin by SDS-PAGE, a single band of 32KDa was obtained (Fig. 2). Hyper immune sera raised against TV and APV could detect this toxin in western blot analysis (Fig. 3). The concentration of the pooled fractions of epsilon toxin was $4.51 \mathrm{mg} / \mathrm{ml}$.

Determination of immune response by indirect ELI SA and MNT: Optimal dilutions for antigen, sera and conjugate were found as 1:100, 1:800 and 1:5000 respectively. ELISA results of different vaccines in terms of $\mathrm{P} / \mathrm{N}$ (positive/ negative) ratio are given in Table 1-4. This was analyzed by one way ANOVA. AOV produced significant and persistent differences in ELISA results. There was a gradual rise from $7^{\text {th }}$ $(1.24 \pm 0.06)$ to $21^{\text {st }}$ day $(2.58 \pm 0.32)$ after which it

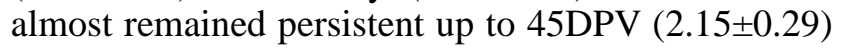
which may remain for longer periods. TV produced an early high antibody titre on $7^{\text {th }}$ day $(1.86 \pm 0.26)$ and peak was on $14^{\text {th }}$ day $(2.75 \pm 0.28)$ with fall on subsequent days $(2.37 \pm 0.42,2.09 \pm 0.36$ and $1.53 \pm 0.46)$ respectively. The value on $45^{\text {th }}$ day $(1.53 \pm 0.46)$ was less than $7^{\text {th }}$ day indicating the fast fall in immune response. APV showed an intermediate trend between TV and AOV. They produced a gradual rise in antibody level from $7^{\text {th }}(1.49 \pm 0.07)$ to $28^{\text {th }}$ day $(2.49 \pm 0.14)$ with a sudden fall on $45^{\text {th }}$ day. Although it produced less response on $45^{\text {th }}$ day compared to $\mathrm{AOV}$, it was significantly greater than TV.

MNT results obtained with different vaccines are shown in Table 5. APV and AOV showed protection at 45th day of post vaccination while TV showed protection only up to 28 th day.

\section{Discussion}

Eradication of enterotoxaemia, an economically important devastating disease of sheep and goats is only having a remote possibility owing to the ubiquitous nature of organism [5]. The very short clinical course of this disease makes therapeutic interventions 


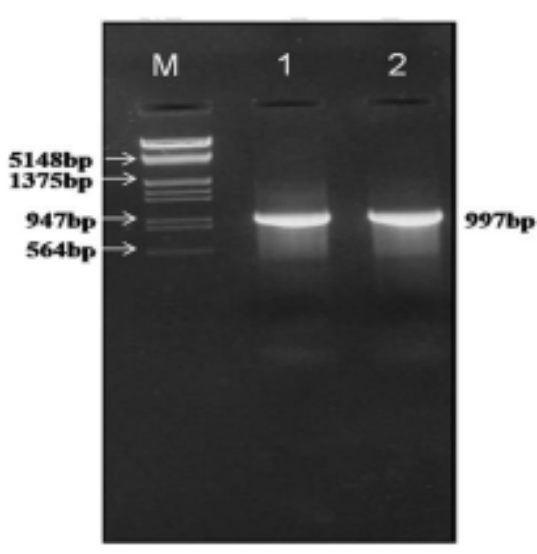

Figure-1. PCR amplification of Clostridium perfringens type $D$ etx gene

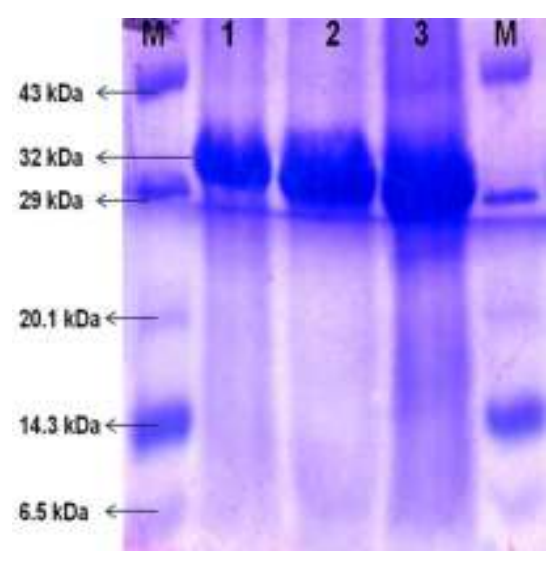

Figure-2. SDS- PAGE analysis of purified epsilon toxin

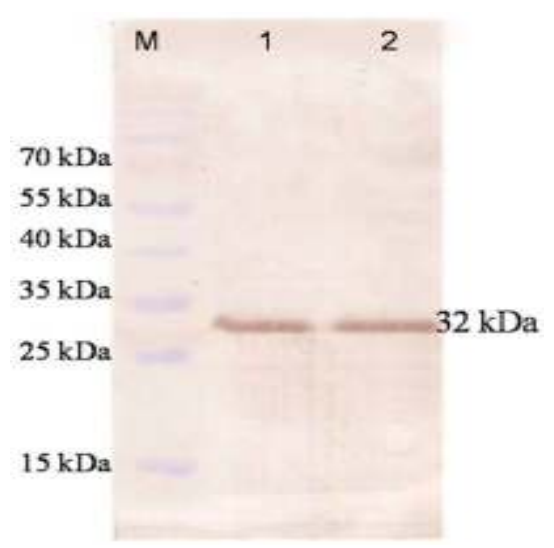

Figure-3. Western Blot analysis of purified epsilon toxin challenging and often impossible. Thus the ideal method of control is vaccination. Inactivated bacterial whole-cell vaccines have been the most widely studied prophylactic mode of treatment for infectious diseases [3]. Though disease can be prevented by these vaccines, immunity lasts only for a short period. Thus due to the difficulty in tracing each animal for booster dose, the current vaccination strategy often fails. In a study evaluating the comparative efficacy of alum precipitated and aluminium hydroxide gel adsorbed enterotoxaemia vaccines in sheep there was no significant difference between these two vaccines [12]. But, it has been proved that duration of immunity provided by alum precipitated oil adjuvant vaccine against hemorrhagic septicemia are longer with less antigenic mass [10]. Keeping these facts new formulation alum precipitated oil adjuvant vaccine was made against enterotoxaemia and compared with presently available toxoid and alum precipitated vaccines. The antigenic mass per dose was maintained same in all vaccines and used for immunization in rabbits. The selection of rabbit was based on the suitability of this animal as a model for testing the efficacy and protective nature of vaccines.

As humoral immune response against epsilon plays an important role in protective immunity against enterotoxaemia [13], only humoral response was assayed. The protective antibody titres against $C$. perfringens epsilon toxin are usually measured using the toxin neutralization test in mice (MNT) $[3,11]$. But this test is cumbersome, very slow, and expensive and can be relatively imprecise as often only a ranged result is obtained. In addition, apart from the ethical considerations of the use of living animals, this assay may suffers from the disadvantages inherent in biological tests such as variation in animal sensitivity [14]. Thus, in the present study indirect ELISA was also used along with MNT to monitor the humoral immune response.

In MNT, the gold standard test to measure protective immunity, AOV and APV showed protection on 45DPV while TV only up to 28DPV revealing the synergistic role of adjuvants in inducing better protective immunity. Similar to this observation [11] and [15] have also reported protection only for 28 days in toxoid immunized animals. Among three vaccines tested by indirect ELISA, AOV produced higher and persistent immune response up to 45DPV which may remain for longer periods. Similar observation regarding the superiority of AOV over APV against hemorrhagic septicaemia was reported earlier [16]. Though the highest immune response was found with TV on $14^{\text {th }}$ day, it dropped suddenly on subsequent days. The titre on $45^{\text {th }}$ day was less than $7^{\text {th }}$ day indicating the fast fall in immune response revealing the reason for short term immunity provided by TV reported by the earlier workers $[11,15]$. APV showed an intermediate trend between TV and AOV. APV elicited better and persistent immune response than toxoid vaccine though it was less than AOV. This was in agreement with the results of [17] and [12] who observed the enhancing effect of alum on anti epsilon production. In present study none of animals immunized showed any untoward reactions at the site of injection. On the contrary to this some authors $[18,19]$ observed adverse reactions following enterotoxaemia vaccination.

\section{Conclusion}

The findings of this study unfolded the synergistic role of adjuvants in induction of better and persistent immune response against enterotoxaemia. The worth mentioning feature of the present study was the development of alum precipitated oil adjuvant enterotoxaemia vaccine which gives better and persistent immune response. However, better understanding of high level of protection which has been observed in AOV needs further exploration in larger scale especially in target species as sheep and goats and on various molecular determinants like isotypes, cytokine assay etc. Such a study can lead to further development of these better vaccines so that these can be finally transferred to hands of farmers.

\section{Author's contribution}

AKR performed the experiments, analysed the data and interpreted the results. VKC conceived the Brainbow 
strategies, supervised the project and edited the paper. STG wrote the manuscript. SSC prepared the antigen for determination of immune response. BJ and MSS assisted in the designing and performance of indirect ELISA and mice neutralization test. All authors discussed the results, implications and commented on the manuscript at all stages. All authors read and approved the final manuscript.

\section{Acknowledgements}

The authors are grateful to the Director and Joint Director (Academic and Research) of Indian Veterinary Research Institute for providing research facilities to carry out the study.

\section{Competing interests}

Authors declare that they have no competing interests.

\section{References}

1. Veschi, J. L. A., Bruzzone, O. A., Losada-Eaton, D. M., Dutra, I. S. and Fernandez-Miyakawa, M. E. (2008) Naturally acquired antibodies against Clostridium perfringens epsilon toxin in goats. Vet. Immunol. Immunopathol., 125: 198-202.

2. McClane, B. A. (2005) Clostridial Enterotoxins. Handbook on Clostridia (Durre P, Ed.). CRC Press, Boca Raton., 385-406.

3. Chandran, D., Naidu, S. S., Sugumar, P., Rani, G. S., Vijayan, S. P., Mathur, D., Garg, L. C. and Srinivasan, V.A. (2010) Development of a recombinant epsilon toxoid vaccine against enterotoxemia and its use as a combination vaccine with live attenuated sheep pox virus against enterotoxemia and sheep pox. Clin. Vaccine Immunol., 17: 1013-1016.

4. Jansen, B. C. (1967) The prevention of enterotoxaemia (pulpy kidney disease) by vaccination. Bull. Off. Int. Epizootiol., 67: 1539-1567.

5. Lobato, F. C., Lima, C. G., Assis, R. A., Pires, P. S., Silva, R. O., Salvarani, F. M., Carmo, A. O., Contigli, C. and Kalapothakis, E. (2010) Potency against enterotoxemia of a recombinant Clostridium perfringens type $\mathrm{D}$ epsilon toxoid in ruminants. Vaccine., 28: 6125-6127.

6. Blood, D. C., Radostits, O. M. and Henderson, J. A. (1983) Veterinary Medicine: a textbook of the diseases of cattle, sheep, goats and horses. $6^{\text {th }}$ ed. Bailliere Tindall, Oxford.

7. Smith, M. C. and Sherman, D. M. (1994) Goat
Medicine, Lea \& Febiger, Pennsylvania, 620.

8. Sunita, S. C. (2011) Studies on immune response against enterotoxaemia vaccine coadjuvanated with aluminium hydroxide gel and saponin. MVSc. thesis submitted to Indian Veterinary Research Institute, Izatnagar.

9. Marrack P., McKee, A. S. and Munks, M. W. (2009) Towards an understanding of the adjuvant action of aluminium. Nat Rev Immunol., 9: 287-93.

10. Bincy, J. (2008) Studies on immunogenicity of haemorrhagic septicaemia vaccine adjuvanated with aluminium hydroxide gel and saponin in mice. MVSc. thesis submitted to Indian Veterinary Research Institute, Izatnagar.

11. Jayaraman, M. S. and Mallick, B. B. (1961) Clostridium welchii type D infection (enterotoxaemia) in sheep and its control. Indian Vet. J., 38: 226-233.

12. Kumar, T. P., Sunitha, G., Mohan, A. V. K. and Reddy, G. H. (2009) Comparative efficacy of alum precipitated and aluminium hydroxide gel adsorbed enterotoxaemia vaccines in sheep. Indian Vet. J., 86: 661-662.

13. Kerry, J. B. and Craig, G. R. (1979) Field studies in sheep with multicomponent clostridial vaccines. Vet. Rec., 105: 551 -554.

14. Henderson, T. G. (1984) The detection of Clostridium perfringens type $\mathrm{D}$ enterotoxin in the intestinal contents of animals by counter immuno electophoresis. NZ. J. Sci., 27: 423-426.

15. Bernath, S., Fabian, K., Kadar, S. G. and Barna, T. (2004) Optimum time interval between first vaccination and booster of sheep for Clostridium perfringens type D. Acta. Vet., 73: 473-475.

16. Jayaraman, M. S. and Setumadhavan, V. (1967) The usefulness of agglutination tests to detect immune and susceptible buffalo calves against Pasteurella multocida type I. Indian Vet. J., 44:271-276.

17. Munoz, J., Schuchardt, L. F., Verwery, W. F. and Scheidy, S. F. (1956) The effect of trypsin activation on the antigenicity and combining power of Clostridium perfringens type D. Proceedings of $59^{\text {th }}$ Anniversary., 62-66.

18. Green, D. S., Green, M. J., Hillyer, M. H. and Morgan, K. L. (1987) Injection site reaction and antibody response in sheep and goats after the use of multivalent clostridial vaccines. Vet. Rec., 120: 436-439.

19. Mamak, N. and Aytekin, I. (2009) Fatal Adverse Reactions of Enterotoxaemia Vaccine in a Sheep Flock. JAVA., 8: 2388-2391. 